\title{
Effects of partial thrombosis on distal aorta after repair of acute DeBakey type I aortic dissection
}

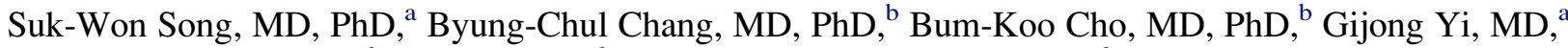 \\ Young-Nam Youn, MD, ${ }^{\mathrm{b}}$ Sak Lee, MD, ${ }^{\mathrm{b}}$ and Kyung-Jong Yoo, MD, PhD ${ }^{\mathrm{b}}$
}

Objective: Prognostic implications of partial thrombosis of the residual aorta after repair of acute DeBakey type I aortic dissection have not been elucidated. We sought to analyze the impact of partial thrombosis on segmental growth rates, distal aortic reprocedures, and long-term survival.

Methods: A total of 118 consecutive patients (55\% were male; mean age, 60 years) with acute DeBakey type I aortic dissection underwent surgical repair (1997-2007). The hospital mortality rate was $17.8 \%$. Survivors underwent serial computed tomography scans. Segment-specific average rates of enlargement were analyzed. Distal reprocedures and patient survival were examined.

Results: Sixty-six patients had imaging data sufficient for growth rate calculations. The median diameters within 2 weeks after repair were as follows: aortic arch, $3.5 \mathrm{~cm}$; descending aorta, $3.6 \mathrm{~cm}$; and abdominal aorta, $2.4 \mathrm{~cm}$. Subsequent growth rates were artic arch, $0.34 \mathrm{~mm} / \mathrm{y}$, descending aorta, $0.51 \mathrm{~mm} / \mathrm{y}$, and abdominal aorta, 0.35 $\mathrm{mm} / \mathrm{y}$. Partial thrombosis of the residual aorta predicted greater growth in the distal aorta $(P=.005)$. There were 13 distal aortic reprocedures ( 5 reoperations, 8 stent graft insertions) for 10 years, and reprocedure-free survival was $66 \%$. Partial thrombosis $(P=.002)$ predicted greater risk of aorta-related reprocedures. Cox analysis revealed that estimated glomerular filtration rate less than $60 \mathrm{~mL} / \mathrm{min} / 1.73 \mathrm{~m}^{2}(P=.030)$, reintubation $(P=.002)$, and partial thrombosis $(P=.023)$ were independent predictors for poor survival.

Conclusion: Partial thrombosis of the false lumen after repair of acute DeBakey type I aortic dissection, compared with complete patency or complete thrombosis, is a significant independent predictor of aortic enlargement, aorta-related reprocedures, and poor long-term survival. (J Thorac Cardiovasc Surg 2010;139:841-7)

Supplemental material is available online.

Acute DeBakey type I aortic dissection (AIAD) remains one of the most challenging conditions for cardiovascular surgeons. Although operative outcomes for acute aortic dissection have continued to improve, ${ }^{1-3}$ the latest report from the International Registry of Acute Aortic Dissection Investigators disclosed a high in-hospital mortality $(23.9 \%){ }^{4}$

The most important goal of the initial AIAD surgery is thought to be immediate survival. Therefore, many surgeons favor a simple and less-invasive operative procedure for such patients. However, several studies showed that

\footnotetext{
From the Department of Thoracic and Cardiovascular Surgery, ${ }^{a}$ Gangnam Severance Hospital, Yonsei University College of Medicine, Seoul, Republic of Korea; and Department of Thoracic and Cardiovascular Surgery, ${ }^{\mathrm{b}}$ Yonsei Cardiovascular Center, Severance Hospital, Yonsei University College of Medicine, Seoul, Republic of Korea.

Disclosures: None.

Received for publication May 2, 2009; revisions received Nov 11, 2009; accepted for publication Dec 3, 2009; available ahead of print Feb 1, 2010.

Address for reprints: Kyung-Jong Yoo, MD, PhD, Yonsei Cardiovascular Center, Severance Hospital, Yonsei University College of Medicine, 134 Shinchon-dong, Seodaemun-ku, 120-752 Seoul, Korea (E-mail: kjy@yuhs.ac). $0022-5223 / \$ 36.00$

Copyright $(C 2010$ by The American Association for Thoracic Surgery doi:10.1016/j.jtcvs.2009.12.007
}

a more radical and extensive operation, such as total arch replacement, regardless of the location of the entry site or extent of pathologic process, did not increase operative morbidity and mortality, and might even improve long-term outcome by decreasing the incidence of residual patent false lumen., ${ }^{2,5-7}$

Residual patent false lumen has recently been reported as a potential risk factor for distal aortic enlargement and poor long-term outcomes. ${ }^{8-10}$ However, the effect of partial thrombosis of the false lumen after AIAD repair on longterm outcomes has not been elucidated. Tsai and colleagues ${ }^{11}$ recently showed that partial thrombosis in patients with acute type B aortic dissection predicts poor survival. We hypothesized that the postoperative status of distal false lumens would be identical to that of acute type B aortic dissection.

The present study assessed the influence of partial thrombosis on late aortic growth rate, distal aortic reprocedures, and late survival to evaluate the long-term outcomes after surgery for AIAD.

\section{PATIENTS AND METHODS \\ Patients}

Between January 1997 and June 2007, 118 consecutive patients (55\% were male; mean age, 60 years) with AIAD underwent surgical treatment at Severance Hospital, Yonsei University Health System, Korea. 


$$
\begin{aligned}
& \text { Abbreviations and Acronyms } \\
& \begin{aligned}
\text { AIAD } & =\text { acute DeBakey type I aortic dissection } \\
\text { CI } & =\text { confidence interval } \\
\text { CT } & =\text { computed tomography } \\
\text { MAAE } & =\text { major adverse aortic event } \\
\text { OR } & =\text { odds ratio }
\end{aligned}
\end{aligned}
$$

\section{Degree of Thrombosis in the Residual False Lumen}

The degree of false lumen thrombosis on CT scans was classified as completely patent if flow was present in the absence of thrombus, as partial thrombosis if both flow and thrombus were present, or as complete thrombosis if no flow was present.

\section{Segmental Aortic Growth Rates}

The segmental aortic growth rate was assessed in patients who had undergone at least $2 \mathrm{CT}$ scans postoperatively with at least 6 months between them. If more than $2 \mathrm{CT}$ scans were performed after hospital discharge, the most recent image was used to determine the aortic growth rate. If an aortic segment had been subjected to aortic reprocedures, the patient was excluded from further aortic growth rate assessment. In each patient, analyses were performed at 3 different aortic levels: the aortic arch, proximal (at the level of the aortic isthmus) descending thoracic aorta, and abdominal aorta. The growth rate was calculated as follows: ${ }^{13,14}$ differences in diameter between the immediate postoperative and most recent measurements divided by the time interval between the 2 measurements.

\section{Statistical Analysis}

All values are expressed as mean \pm standard deviation. Between-group differences in clinical and morphologic variables were analyzed by the chisquare test, Fisher exact test, unpaired $t$ test, or Mann-Whitney $U$ test. Multivariate logistic regression analysis was performed to identify independent risk factors for mortality and partial thrombosis. The time-related events studied included MAAEs and death after hospital discharge. Freedom from these time-related events was estimated by the nonparametric actuarial Kaplan-Meier method. Actuarial survival and freedom from reoperation on the distal aorta for all patients with acute type I aortic dissections are also given. All statistical analyses were performed using SPSS 12.0.1 for Windows (SPSS, Inc, Chicago, Ill).

\section{RESULTS}

\section{Risk Factors for Operative Mortality}

A total of 21 patients (17.8\%) died after surgery. Cause of deaths included multiorgan failure $(\mathrm{n}=9)$, postoperative bleeding $(n=7)$, pulmonary complication $(n=2)$, neurologic complications $(\mathrm{n}=2)$, and heart failure $(\mathrm{n}=2)$. In the univariate analysis, peripheral arterial obstructive disease, chronic renal failure, aortic root diameter, ascending aorta diameter, aortic arch diameter, and renal dysfunction (estimated glomerular filtration rate) were risk factors for operative mortality. Multivariate logistic regression analysis revealed that an enlarged aortic root $50 \mathrm{~mm}$ or greater was an independent risk factor for operative mortality $(P=.021)$ (Table E1).

\section{Degree of Thrombosis in the Residual False Lumen}

Of the 97 survivors, 85 (87.6\%) underwent enhanced CT scans within 2 weeks after surgery. Nineteen patients $(22.4 \%)$ did not undergo enhanced CT scans during the follow-up period (12 patients underwent only simple CT scans because of renal insufficiency or an allergy to the contrast medium, and 7 patients refused postoperative CT scans).

A total of 66 patients $(68 \%)$ had sufficient imaging data to determine aortic growth rates. Among these patients, the incidence of residual patent false lumen on initial postoperative CT examination was $77 \%$ (51/66). Twenty-four 
$(47.1 \%)$ of the 51 patients with residual patent false lumens had a completely patent false lumen in the thoracoabdominal aorta. In the remaining 27 patients $(52.9 \%)$, partial thrombosis was observed in the descending thoracic or abdominal aortas. Only 15 patients $(23 \%)$ had complete thrombosis in the thoracoabdominal aorta.

Partial thrombosis occurred more frequently after ascending or hemiarch replacement than total arch replacement (55\% [47/86] vs $34 \%$ [11/32], $P=.0001)$. The extent of surgery was an independent predictor for partial thrombosis of the distal aortic false lumen in this study $(P=.024)$.

\section{Segment-Specific Aortic Growth Rate}

A total of 252 CT scans in 66 patients who had adequate imaging data were analyzed for segmental aortic growth rate. The mean overall CT follow-up period was $2.9 \pm 2.7$ years (median, 1.6 years; range, 0.3-10.1 years). The median diameters within 2 weeks after repair were as follows: aortic arch, $3.5 \mathrm{~cm}$; descending aorta, $3.6 \mathrm{~cm}$; and abdominal aorta, $2.4 \mathrm{~cm}$. The median segmental aortic growth rate for the aortic arch, proximal descending thoracic aorta, and abdominal aorta was $0.34,0.51$, and $0.35 \mathrm{~mm}$ per year, respectively (Table 1). The mean growth rate was higher in the partially thrombosed group than in the completely patent or completely thrombosed group, and between-group differences were significant at all segments of the distal aorta. The segmental aortic growth rate of the distal aorta was highest at the proximal descending thoracic aorta and with partial thrombosis in the false lumen. The distal aorta of the completely thrombosed group frequently became a single-barrel chamber because the thrombosed false lumen disappeared during the follow-up period. This later disappearance of the thrombosis led to negative aortic growth found in the thrombosed group.

Most patients in the completely thrombosed group showed slight or no decrease in aortic diameter. In contrast, most patients in the partially thrombosed group showed rapid aortic enlargement.

\section{Long-Term Survival}

Thirteen patients died during the follow-up period. The most common cause of death was related to neurologic complications ( 2 intracranial hemorrhages and 3 cerebral infarctions). The second leading cause was aorta-related death $(\mathrm{n}=4)$. Two patients $(15.4 \%)(1$ in the partially thrombosed group and 1 in the completely patent group) died of aortic aneurysm ruptures in the distal aorta. Two patients died of graft infections. Three patients died of cardiac failure, including myocardial infarction $(\mathrm{n}=1)$, mediastinitis $(\mathrm{n}=1)$, and endocarditis $(\mathrm{n}=1)$. One patient died of acute respiratory distress syndrome. Actuarial survival was $85.5 \%$ at 1 year, $67.8 \%$ at 5 years, and $67.8 \%$ at 10 years (Figure 1, $A)$. Cuve mortality after surgery revealed that the partially thrombosed group had the worst prognosis (Figure 1,B).

\section{Risk Factors for Poor Survival}

Estimated glomerular filtration rate less than $60 \mathrm{~mL} / \mathrm{m}^{2}$, malperfusion, hemodynamic compromise, renal failure, peripheral arterial obstructive disease, old age, postoperative complication, readmission to intensive care unit, reintubation, and partial thrombosis in the false lumen of distal aorta were risk factors for poor survival.

Cox proportional hazard analysis revealed that estimated glomerular filtration rate less than $60 \mathrm{~mL} / \mathrm{m}^{2}$ (odds ratio [OR], 4.840; 95\% confidence interval [CI], 1.161-20.167; $P=.030)$, need for reintubation (OR, 7.491; 95\% CI, 2.071-27.096; $P=.002$ ), and partial thrombosis in the false lumen of distal aorta (OR, 6.484; 95\% CI, 1.300-32.346; $P=.023)$ were independent risk factors for poor survival (Table 2).

\section{Major Adverse Aortic Events}

We defined MAAEs as the need for distal aorta-related reoperation, endovascular aortic repair, aortic rupture, or graft infection during the 10-year follow-up period. There were 13 distal aortic reprocedures ( 5 reoperations and 8 endovascular aortic repairs), 2 distal aortic ruptures, and 1 graft infection. Two distal aortic ruptures occurred at postoperative days 1781 and 1113 . Both patients died immediately after arrival at the emergency department of our institute (Yonsei University Health System). Four MAAEs occurred in the completely patent group, 12 MAAEs occurred in the partially thrombosed group, and 1 MAAE occurred in the completely thrombosed group (Table 3).

\section{Late Reprocedures on the Distal Aorta}

Our criterion for reprocedures on the distal aorta was an aortic diameter of more than $60 \mathrm{~mm}$. During the follow-up

TABLE 1. Segmental aortic growth rate (millimeters/year)

\begin{tabular}{|c|c|c|c|c|c|}
\hline $\begin{array}{c}\text { Aortic segment } \\
\quad(n=66)\end{array}$ & $\begin{array}{c}\text { Complete } \\
\text { patency } \\
(\mathrm{n}=\mathbf{2 4 , 3 6} \%) \\
\end{array}$ & $\begin{array}{c}\text { Partial } \\
\text { thrombosis } \\
(\mathrm{n}=\mathbf{2 7}, \mathbf{4 1} \%)\end{array}$ & $\begin{array}{c}\text { Complete } \\
\text { thrombosis } \\
(\mathrm{n}=\mathbf{1 5}, \mathbf{2 3} \%)\end{array}$ & Median & $P$ value \\
\hline Aortic arch & $0.79 \pm 6.41$ & $2.13 \pm 4.57$ & $-1.88 \pm 5.11$ & 0.34 & .049 \\
\hline DTA & $3.81 \pm 5.58$ & $5.52 \pm 9.05$ & $-0.89 \pm 3.93$ & 0.51 & .005 \\
\hline Abdominal aorta & $0.93 \pm 2.46$ & $2.80 \pm 4.09$ & $-0.34 \pm 3.36$ & 0.35 & .015 \\
\hline
\end{tabular}

DTA, Descending thoracic aorta. 

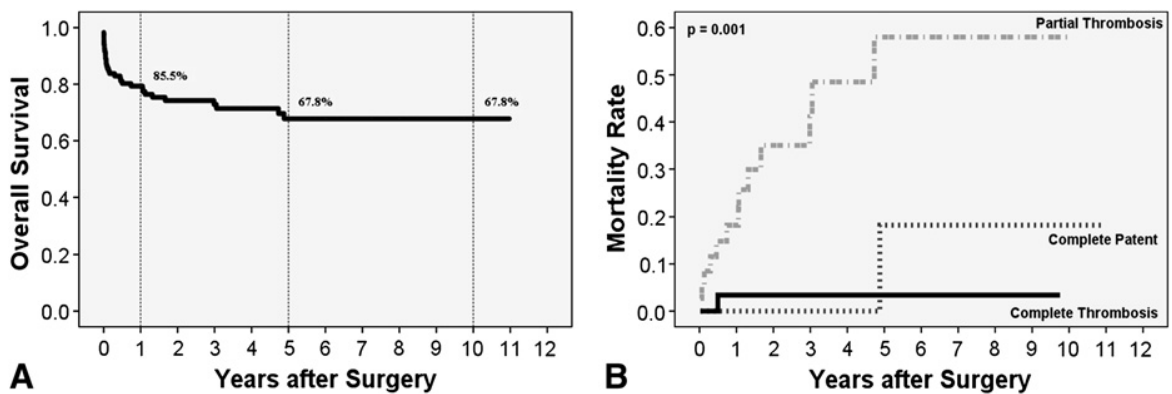

FIGURE 1. A, Overall survival after surgical repair of AIAD. B, Cumulative mortality rate after surgical repair of AIAD according to the thrombosis degree of false lumen in the distal aorta.

period, 13 patients $(13.4 \%)$ underwent 13 late reprocedures on the distal aorta (on the aortic arch and descending thoracic aorta in 2 patients, descending thoracic aortas in 6 patients, thoracoabdominal aortas in 2 patients, and abdominal aortas in 3 patients). Nine of the 13 patients $(69.2 \%)$ who underwent late reprocedures on the distal aorta had partial thrombosis in the false lumen, 3 patients had completely patent false lumens, and only 1 patient had a completely thrombosed false lumen that required late a reprocedure on the distal aorta. All reprocedures were performed electively, and there was no periprocedural death associated with these reprocedures. Freedom from distal aortic reprocedures for all

TABLE 2. Risk factors for poor survival

\begin{tabular}{|c|c|c|c|c|}
\hline \multirow[b]{2}{*}{ Variables } & \multirow[b]{2}{*}{$P$ value } & \multicolumn{3}{|c|}{ Cox proportional hazard analysis } \\
\hline & & Odds ratio & $\begin{array}{c}95 \% \text { confidence } \\
\text { interval }\end{array}$ & $P$ value \\
\hline $\begin{array}{c}\mathrm{eGFR}<60 \mathrm{~mL} / \\
\mathrm{min} / \mathrm{m}^{2}\end{array}$ & $<.0001$ & 4.840 & $1.161-20.167$ & .030 \\
\hline Malperfusion & .031 & & & \\
\hline $\begin{array}{l}\text { Hemodynamic } \\
\text { compromise }\end{array}$ & .029 & & & \\
\hline Renal failure & .001 & & & \\
\hline PAOD & .010 & & & \\
\hline Age & $<.05$ & & & \\
\hline $\begin{array}{l}\text { Postoperative } \\
\text { complications }\end{array}$ & $<.0001$ & & & \\
\hline $\begin{array}{l}\text { Readmission to } \\
\text { ICU }\end{array}$ & .040 & & & \\
\hline Reintubation & .003 & 7.491 & $2.071-27.096$ & .002 \\
\hline $\begin{array}{l}\text { DTA-FL partial } \\
\text { thrombosis }\end{array}$ & .001 & 6.484 & $1.300-32.346$ & .023 \\
\hline \multicolumn{5}{|c|}{$\begin{array}{l}D T A-F L \text {, Descending thoracic aorta-false lumen; } e G F R \text {, Estimated glomerular filtra- } \\
\text { tion rate; } I C U \text {, intensive care unit; } P A O D \text {, peripheral arterial obstructive disease. } \\
\text { Evaluated variables were as follows: preoperative variables (gender, grade of aortic } \\
\text { insufficiency, aortic root diameter, ascending aorta diameter, aortic arch diameter, } \\
\text { presence of coronary artery obstructive disease, peripheral arterial obstructive } \\
\text { disease, chronic obstructive pulmonary disease, smoking, diabetes mellitus, hyperten- } \\
\text { sion, chronic renal failure, Marfan syndrome, prior sternotomy, prior neurologic } \\
\text { event, new onset neurologic event, hemodynamic compromise, and malperfusion } \\
\text { syndrome), intraoperative variables (extent of surgery, type of surgery for aortic } \\
\text { root, cardiopulmonary bypass time, circulatory arrest time, cerebral perfusion tech- } \\
\text { nique, and cannulation site), postoperative variables (need of reintubation, readmission } \\
\text { to intensive care unit, and postoperative complication), and follow-up variables (aortic } \\
\text { growth rate, and false lumen partial thrombosis in the residual aorta). }\end{array}$} \\
\hline
\end{tabular}

hospital survivors was $94.6 \%$ at 1 year, $78.8 \%$ at 5 years, and $66.1 \%$ at 10 years (Figure $2, A$ ). The distal aortic reprocedure rate was significantly higher in the partially thrombosed group than in the completely thrombosed group (Figure 2, B). However, group difference between the partially thrombosed and completely patent groups was not significant $(P>.05)$. All 8 endovascular aortic repairs were performed on the descending thoracic aorta. There was no endoleak, and all patients were alive at the last follow-up. Of the 118 patients who underwent surgery for AIAD, 10 had Marfan syndrome. In-hospital mortality for these patients was zero, and no distal aortic reoperation was performed in patients with Marfan syndrome.

\section{DISCUSSION}

Although the immediate surgical outcomes of acute type I aortic dissection have recently improved with advances in surgical techniques and perioperative care, ${ }^{1-3}$ the longterm fate of residual false lumen of the distal aorta after repair of AIAD has not been clearly elucidated.

Residual patent false lumen is a well-known risk factor for future aortic enlargement ${ }^{7-9}$ and has been reported to be related with unresected intimal tear, leakage from the distal anastomosis site needle holes, and reentry in the distal aorta after surgical repair of AIAD. Although complete resection of all entry tears is required for complete thrombosis of the false lumen, initial surgery for AIAD fails to achieve this

TABLE 3. Major adverse aortic events

\begin{tabular}{llllc}
\hline \multicolumn{1}{c}{ DTA-FL } & Reoperation & EVAR & $\begin{array}{c}\text { Aortic } \\
\text { rupture }\end{array}$ & $\begin{array}{c}\text { Graft } \\
\text { infection }\end{array}$ \\
\hline $\begin{array}{l}\text { Complete } \\
\text { patency }\end{array}$ & TAAA (1) & DTA (2) & DTA (1) & 0 \\
$\begin{array}{l}\text { Partial } \\
\text { thrombosis }\end{array}$ & $\begin{array}{c}\text { TAR + DTA (2) } \\
\text { TAAA (1) }\end{array}$ & DTA (3) & DTA (1) & 1 \\
$\begin{array}{l}\text { Complete } \\
\text { thrombosis }\end{array}$ & AAA (1) & & \\
$\begin{array}{l}A A A, \text { Abdominal aortic aneurysm; } D T A, \text { descending thoracic aorta; } D T A-F L, \text { descend- } \\
\text { ing thoracic aorta-false lumen; } E V A R, \text { endovascular aortic repair; } T A A A, \text { thoracoabdo- } \\
\text { minal aortic aneurysm; } T A R, \text { total arch replacement. }\end{array}$ & DTA (1) & 0 &
\end{tabular}



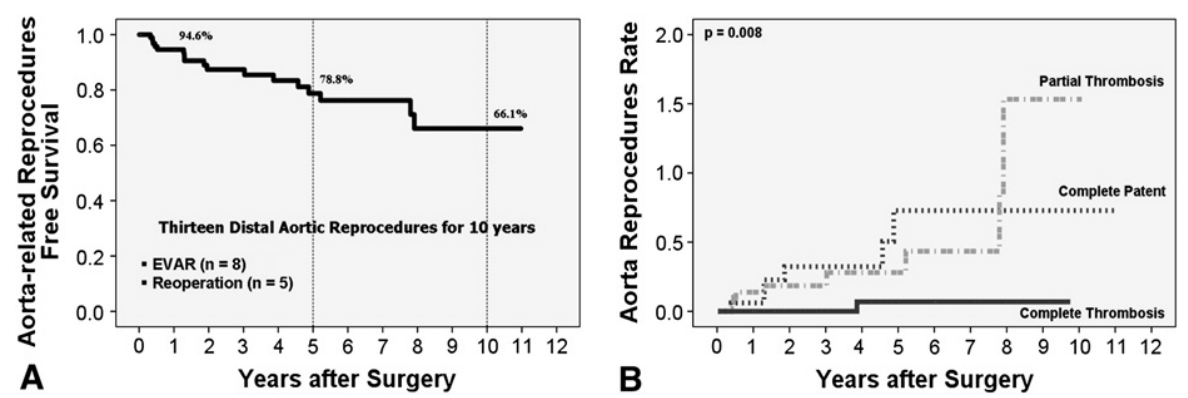

FIGURE 2. A, Aorta-related reprocedure-free survival after surgical repair of AIAD. B, Cumulative aorta-related reprocedure rate after surgical repair of AIAD according to the thrombosis degree of false lumen in the distal aorta. EVAR, Endovascular aneurysm repair.

objective, particularly in patients with primary entry or reentry located in the descending thoracic or abdominal aorta.

\section{Partial Thrombosis}

We hypothesized that the morphologic status of distal residual aorta after repair of an AIAD would mirror a type $\mathrm{B}$ aortic dissection. Tsai and colleagues ${ }^{11}$ reported that the natural course of false lumen partial thrombosis in an acute type B aortic dissection has a worse prognosis than that of the completely patent group. In our present study, the result is concordant with Tsai and colleagues' finding. In other words, partial thrombosis of the false lumen after repair of AIAD is an independent risk factor for rapid aortic dilatation, aorta-related reprocedures, and overall survival.

Formation of a partial thrombosis in the distal aorta after surgery may occlude these proximal tears, impede outflow, and in the most extreme situation result in a blind sac (Figure E1). An increase in false lumen pressure will increase wall tension, which may elevate the risk of distal aortic aneurismal change and eventually result in rupture. Previous studies suggested a direct relationship between intraluminal thrombosis and the risk of rupture of an abdominal aortic aneurysm as a result of hypoxia of the arterial wall adjacent to intraluminal thrombus, which leads to increased local inflammation, neovascularization, and localized wall weakening. ${ }^{12-15}$ We showed in our data that partial thrombosis is an independent risk factor for rapid aortic growth and an increase in aortic reprocedures.

\section{Total Arch Replacement}

Several groups that routinely use total arch replacement recently reported excellent operative outcomes, with mortality ranging from $4.7 \%$ to $10 \% .^{2,6,7}$ In the present study, inhospital mortality for patients who underwent total arch replacement was not higher than that for patients who underwent ascending aorta or hemiarch replacement $(P>.05)$.

Some groups justify routine replacement of the total aortic arch for AIAD by the decreased incidence of residual patent false lumens, irrespective of the site of entry tear. ${ }^{2,5-7}$ The benefit of this surgical strategy is complete resection of a small, invisible entry tear located in the aortic arch. ${ }^{7}$ The incidence of residual patent false lumen was $77 \%(51 / 66)$ in our series of patients. This was in accordance with results of previous studies in which total arch replacement was performed in selective patients. ${ }^{9,10,16-18}$ The incidence of residual patent false lumen was higher than that reported by other groups who performed total arch replacement in all patients with AIAD. 2,6,7

Our study revealed that total arch replacement had a lower incidence of partial thrombosis at the proximal descending thoracic aortic level and showed favorable outcome in aortic enlargement and aortic reprocedures compared with ascending or hemiarch replacement.

Other reported risk factors for residual patent false lumen after surgery for AIAD include Marfan syndrome, preoperative extension of the false lumen, male gender, and enlarged aortic diameter. ${ }^{2,8}$ In the present study, surgical extent was the only risk factor for residual false lumen and partial thrombosis after surgery for AIAD.

\section{Aortic Reprocedures}

Our series had a high incidence of distal reprocedures (33.9\% cumulative reoperation rate at 10 years after surgery), similar to incidences reported by other groups who performed total arch replacement only in selective patients. ${ }^{19,20}$ Reoperation-free rates reported by groups performing routine total arch replacement for AIAD was higher than for selective total arch replacement. ${ }^{5,7}$ In our data, patients with total arch replacement showed a lower incidence of partial thrombosis at the level of the proximal descending thoracic aorta $(34 \%)$ and did not have any aortarelated reprocedure during the follow-up periods. Although it remains unclear whether this approach can improve late survival, we believe that surgical extent at initial repair can be a determinant of the natural history of the distal aorta after surgery for AIAD. 
However, elderly patients tend to have more thrombosed false lumens than young patients after initial surgery for AIAD. Therefore, especially when a patient is elderly or has various preoperative morbidities, ascending or hemiarch replacement seems to be sufficient for patients' survival. Other risk factors for aortic enlargement or distal aortic reoperation after surgery for AIAD include nonresection of the entry site, distal extension of a dissection, and Marfan syndrome. ${ }^{20-23}$ Therefore, we believe that in younger patients, or patients with Marfan syndrome, total arch replacement should be performed to decrease the need for late reoperation.

Zierer and colleagues ${ }^{21}$ recently reported that uncontrolled hypertension is a risk factor for late aortic enlargement. Careful antihypertensive therapy seems to be important for the prevention of later aortic enlargement.

DeBakey and colleagues ${ }^{24}$ reported that rupture of the distal aorta was the most common cause of death in patients with AIAD, accounting for $29.3 \%$ of late deaths. In our series, there were 2 patients who died of rupture of the distal aorta during the follow-up periods (at postoperative day 1781 after ascending aorta replacement and postoperative day 1113 after hemiarch replacement). The maximum diameter of the descending thoracic aorta was $79 \mathrm{~mm}$ and $46 \mathrm{~mm}$, respectively. The first patient was in the completely patent group, and the second patient was in the partially thrombosed group. Our impression is that although the diameter of distal aorta was less than 5 or $6 \mathrm{~cm}$, partial thrombosis of the distal false lumen might have been an aggravating factor for aortic rupture.

Although careful follow-up is mandatory to prevent rupture of the distal aorta, the decision to perform aortic reprocedures in a stable, asymptomatic patient is another important issue. For timely reprocedures, we must take into account not only comorbidities and aortic diameter but also the status of the residual false lumen.

Favorable results of endovascular treatment for acute or chronic aortic dissection were recently reported, with high rates of success with false lumen thrombosis. ${ }^{25}$ When we consider aorta-related reprocedures, endovascular treatment can be an effective alternative especially for elderly or severely compromised patients who are at higher risk.

\section{Study Limitations}

Our study had several limitations. First, follow-up CT scans were performed on only 66 patients $(68 \%)$ with variable intervals after surgery. We could not analyze the cumulative rate of aortic dilatation or time-related change of thrombosis characteristics in the false lumen. Second, initial and follow-up CT scans after discharge were not standardized at our hospital and referring hospitals. Third, the follow-up period was relatively short. The mean follow-up period was only 3.5 years, and the results were not sufficient to show long-term outcomes after surgery for AIAD. With a longer follow-up period, a difference in the distal reoperation-free rate may become evident among patients with various degrees of thrombosis in the false lumen, and patients with false lumen partial thrombosis may have poorer long-term outcomes. Further studies involving larger numbers of patients with a longer follow-up period are required.

\section{CONCLUSIONS}

The present study revealed that partial thrombosis in the false lumen is a significant independent risk factor for a rapidly growing distal aorta, poor long-term survival, and aortarelated reprocedures after surgical repair for AIAD. In terms of the extent of surgery, total arch replacement has a more favorable outcome in aortic enlargement and aortic reprocedures compared with ascending or hemiarch replacement. We believe that more radical resection of diseased aorta considering a patient's age and comorbidities, more meticulous follow-up, and time-appropriate aortic reprocedures may provide a more favorable long-term prognosis even in patients with a partial thrombosis in the false lumen after surgery for AIAD.

The authors thank Sun-Hee Lim, RN, for collecting the data used in this article.

\section{References}

1. Westaby S, Saito S, Katsumata T. Acute type A dissection: conservative methods provide consistently low mortality. Ann Thorac Surg. 2002;73:707-13.

2. Takahara Y, Sudo Y, Mogi K, Nakayama M, Sakurai M. Total aortic arch grafting for acute type A dissection: analysis of residual false lumen. Ann Thorac Surg. 2002;73:450-4

3. Hata M, Shiono M, Sezai A, Iida M, Negishi N, Sezai Y. Type A acute aortic dissection: immediate and mid-term results of emergency replacement with the aid of gelatin resorcin formalin glue. Ann Thorac Surg. 2004;78:853-7.

4. Rampoldi V, Trimarchi S, Eagle KA, Nienaber CA, Oh JK, Bossone E, et al. Simple risk models to predict surgical mortality in acute type A aortic dissection: the International Registry of Acute Aortic Dissection score. Ann Thorac Surg. 2007; 83:55-61.

5. Kazui T, Washiyama N, Muhammad BA, Terada H, Yamashita K, Takinami M, et al. Extended total arch replacement for acute type A aortic dissection: experience with seventy patients. J Thorac Cardiovasc Surg. 2000;119:558-65.

6. Urbanski PP, Siebel A, Zacher M, Hacker RW. Is extended aortic replacement in acute type A dissection justifiable? Ann Thorac Surg. 2003;75:525-9.

7. Hirotani T, Nakamichi T, Munakata M, Takeuchi S. Routine extended graft replacement for an acute type A aortic dissection and the patency of the residual false channel. Ann Thorac Surg. 2003;76:1957-61.

8. Yeh CH, Chen MC, Wu YC, Wang YC, Chu JJ, Lin PJ. Risk factors for descending aortic aneurysm formation in medium-term follow-up of patients with type A aortic dissection. Chest. 2003;124:989-95.

9. Immer FF, Hagen U, Berdat PA, Eckstein FS, Carrel TP. Risk factor for secondary dilation of the aorta after acute type A aortic dissection. Eur J Cardiothorac Surg. 2005;27:654-7.

10. Halstead JC, Meier M, Etz C, Spielvogel D, Bodian C, Wurm M, et al. The fate of the distal aorta after repair of acute type A aortic dissection. J Thorac Cardiovasc Surg. 2007; 133:127-35

11. Tsai TT, Evangelista A, Nienaber CA, Myrmel T, Meinhardt G, Cooper JV, et al. Partial thrombosis of the false lumen in patients with acute type B aortic dissection. $N$ Engl J Med. 2007;357:349-59.

12. Satta J, Laara E, Juvonen T. Intraluminal thrombus predicts rupture of an abdominal aortic aneurysm. J Vasc Surg. 1996;23:737-9.

13. Wolf YG, Thomas WS, Brennan FJ, Goff WG, Sise MJ, Bernstein EF. Computed tomography scanning findings associated with rapid expansion of abdominal 
aortic aneurysms. J Vasc Surg. 1994;20:529-35 [Erratum, J Vasc Surg. 1995;21: 295.].

14. Kazi M, Thyberg J, Religa P, Roy J, Eriksson P, Hedin U, et al. Influence of intraluminal thrombus on structural and cellular composition of abdominal aortic aneurysm wall. J Vasc Surg. 2003;38:1283-92.

15. Vorp DA, Lee PC, Wang DH, Makaroun MS, Nemoto EM, Ogawa S, et al. Association of intraluminal thrombus in abdominal aortic aneurysm with local hypoxia and wall weakening. J Vasc Surg. 2001;34:291-9.

16. Fann JI, Smith JA, Miller DC, Mitchell RS, Moore KA, Grunkemeier G, et al. Surgical management of aortic dissection during a 30-year period. Circulation. 1995; 92(Suppl). II113-21.

17. David TE, Armstrong S, Ivanov J, Barnard S. Surgery for acute type A aortic dissection. Ann Thorac Surg. 1999;67:1999-2001.

18. Fattori R, Bacchi-Reggiani L, Bertaccini P, Napoli G, Fusco F, Longo M, et al. Evolution of aortic dissection after surgical repair. Am J Cardiol. 2000;86:868-72.

19. Sabik JF, Lytle BW, Blackstone EH, McCarthy PM, Loop FD, Cosgrove DM. Long-term effectiveness of operations for ascending aortic dissections. J Thorac Cardiovasc Surg. 2000;119:946-62.

20. Kirsch M, Soustelle C, Houël R, Hillion ML, Loisance D. Risk factor analysis for proximal and distal reoperations after surgery for acute type A aortic dissection. J Thorac Cardiovasc Surg. 2002;123:318-25.

21. Zierer A, Voeller RK, Hill KE, Kouchoukos NT, Damiano RJ Jr, Moon MR. Aortic enlargement and late reoperation after repair of acute type A aortic dissection. Ann Thorac Surg. 2007;84:479-86.

22. Bachet JE, Termignon JL, Dreyfus G, Goudot B, Martinelli L, Piquois A, et al. Aortic dissection: prevalence, cause, and results of late reoperation. J Thorac Cardiovasc Surg. 1994;108:199-206.

23. Kazui T, Washiyama N, Bashar AH, Terada H, Suzuki T, Ohkura K, et al. Surgical outcome of acute type A aortic dissection: analysis of risk factors. Ann Thorac Surg. 2002;74:75-82.

24. DeBakey ME, McCollum CH, Crawford ES, Morris GC Jr, Howell J, Noon GP, et al. Dissection and dissecting aneurysms of the aorta: 20-year follow-up of 527 patients treated surgically. Surgery. 1982;92:1118-34.

25. Kusagawa H, Shimono T, Ishida M, Suzuki T, Yasuda F, Yuasa U, et al. Changes in false lumen after transluminal stent-graft placement in aortic dissection: six years' experience. Circulation. 2005;111:2951-7.

\section{Discussion}

Dr Anthony Estrera (Houston, Tex). I have nothing to disclose. As referenced by Dr Song, a recent evaluation of the IRAD experience demonstrated the potentially detrimental effect of the partially thrombosed false lumen in aortic dissection. This study by Song and colleagues analyzed this effect in relation to post-repair of acute type I aortic dissection. The strength of this study is not in the early results but rather the late follow-up. Song and colleagues determined, in addition to decreased late survival, greater aortic growth, and more frequent aortic reinterventions were observed in those patients with a partially thrombosed false lumen, giving us some potential causes for this increased late mortality.

As interesting as the fact of the detrimental effect of the partially thrombosed false lumen was also the apparent beneficial effect, although not significant in their study, of the completely thrombosed false lumen. This should incite us to try to better understand how the aorta remodels after dissection.

This study reiterates the importance of long-term follow-up required with aortic dissection and further emphasizes that aortic diameter should not be the only factor followed in these patients. Determining when to intervene will depend on physiologic factors, such as blood pressure, patency of the false lumen, and ultimately molecular factors, as well as what we currently use now, size, or aortic diameter. Dr Song, I have 3 questions.

First, partial thrombosis was defined as present in the descending thoracic or abdominal aorta. Did the extent or location of the partially thrombosed aorta make a difference?
Second, in your follow-up, was blood pressure controlled and were other medications tracked, such as those that might affect the dysregulation of the smooth muscle cells in the media (eg, angiotensin receptor blockers)?

Last, on the basis of this study, can you advocate replacing the arch in all type I aortic dissections to gain the long-term benefits? If not, how do you decide when to replace the arch during acute dissection?

Although the series was small and radiographic follow-up was limited, I do congratulate Dr Song and colleagues for a well-written and presented article.

Dr Song. Your first question was about the differing effect of long- or short-segment involvement of partial thrombosis or how thrombosis location can differentiate between long-term or early outcome. I didn't differentiate between long- and short-segment involvement of the partial thrombosis; however, if it was according to the occlusion of the reentry tears, long-segment involvement of partial thrombosis will increase the pressure in the false lumen, the wall tension, and the risk of aneurysmal change. Therefore, I think that long-segment involvement of partial thrombosis would have a poorer outcome compared with short-segment involvement.

The second question is regarding antihypertensive therapy. In our data, almost all patients receive beta-blockers or alpha-blockers and other antihypertensive drugs after surgery. And, almost all patients had tightly controlled blood pressure. As you know, careful antihypertensive therapy seems to be another important issue for the prevention of late aortic enlargement or reprocedure rate or long-term survivor. It is a very important issue, I think. However, I didn't analyze the impact of angiotensin II receptor blocker, for which many physicians have great interest. It will be important to analyze the effect of angiotensin receptor blockers after surgical repair of aortic dissection.

Your final question is about total arch replacement and the indication of total arch replacement. In the absence of intimal tear in the aortic arch, total arch replacement has been argued so far, and recent reports showed similar early outcome after total arch replacement compared with ascending or hemiarch replacement. The longterm result after total arch replacement is better than that of ascending or hemiarch replacement. In the past years in our institute, we performed ascending or hemiarch replacement if the intimal tear was not present in the aortic arch. However, recently I am trying to perform total arch replacement routinely regardless of the intimal tearing site, and the early result was similar to that of ascending or hemiarch replacement. However, if the patient is elderly and has various comorbidities, ascending or hemiarch replacement seems sufficient for patient survival.

Dr Alberto Pochettino (Philadelphia, $\mathrm{Pa}$ ). I enjoyed your talk. It is interesting how much of the data confirm what many of us have seen in our experience, that when repair of an acute type A/DeBakey I dissection is completed, the patient is not done, but there is more morbidity and mortality down the road. The question is simple. Did you try by using endovascular stent grafting to change a partial thrombosis into a full thrombosis?

Dr Song. Actually, in Korea, the thoracic endograft has not been approved yet, and one homemade endograft is being developed right now, but it is not widely used, and the study after stent grafting has not been performed. 

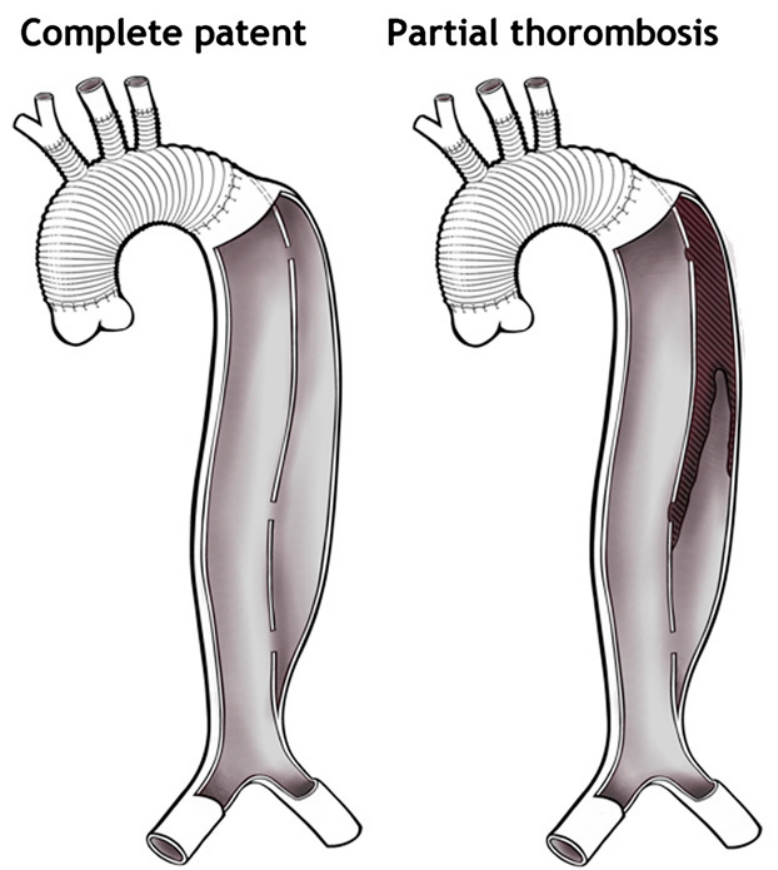

\section{Complete thrombosis}

FIGURE E1. Effect of thrombosis degree on distal aorta after repair of AIAD.

TABLE E1. Risk factor analysis of operative mortality after repair of acute DeBakey type I aortic dissection

\begin{tabular}{lcccc}
\hline & & \multicolumn{3}{c}{ Multivariate analysis } \\
\cline { 2 - 5 } \multicolumn{1}{c}{ Variables } & $\boldsymbol{P}$ value & $\begin{array}{c}\text { Odds } \\
\text { ratio }\end{array}$ & $\begin{array}{c}\mathbf{9 5} \% \text { confidence } \\
\text { interval }\end{array}$ & $\begin{array}{c}\boldsymbol{P} \\
\text { value }\end{array}$ \\
\hline PAOD & .035 & & & \\
Renal failure & .010 & & & \\
Aortic root diameter & .034 & 1.200 & $1.016-1.417$ & .032 \\
Ascending aorta diameter & .042 & & & \\
Aortic arch diameter & .035 & & & \\
eGFR & .011 & & & \\
\hline
\end{tabular}

eGFR, Estimated glomerular filtration rate; $P A O D$, peripheral arterial obstructive disease. Evaluated preoperative variables (gender, grade of aortic insufficiency, aortic root diameter, ascending aorta diameter, aortic arch diameter, presence of coronary artery obstructive disease, peripheral arterial obstructive disease, chronic obstructive pulmonary disease, smoking, diabetes mellitus, hypertension, chronic renal failure, estimated glomerular filtration rate, Marfan syndrome, prior sternotomy, prior neurologic event, new-onset neurologic event, hemodynamic compromise, and malperfusion syndrome), and intraoperative variables (extent of surgery, type of surgery for aortic root, cardiopulmonary bypass time, circulatory arrest time, cerebral perfusion technique, and cannulation site). 